\title{
The Internet Hospital Plus Drug Delivery Platform for Health Management During the COVID-19 Pandemic: Observational Study
}

Liang Ding ${ }^{*}$, PhD; Qiuru She ${ }^{2 *}$, BS; Fengxian Chen ${ }^{2}$, BS; Zitong $\mathrm{Chen}^{2}$, BS; Meifang Jiang ${ }^{2}$, BS; Huasi Huang ${ }^{2}$, BS; Yujin $\mathrm{Li}^{2}$, MS; Chaofeng $\mathrm{Liao}^{2}$, BS

\footnotetext{
${ }^{1}$ Clinical Trial and Research Center, People's Hospital of Baoan Shenzhen, Shenzhen, China

${ }^{2}$ Department of Pharmacy, People's Hospital of Baoan Shenzhen, Shenzhen, China

*these authors contributed equally
}

\section{Corresponding Author:}

Chaofeng Liao, BS

Department of Pharmacy, People's Hospital of Baoan Shenzhen

118 Longjing 2nd Road

Shenzhen, 518101

China

Phone: 8618926480093

Email: bayylcf@126.com

\section{Abstract}

Background: Widespread access to the internet has boosted the emergence of online hospitals. A new outpatient service called "internet hospital plus drug delivery" (IHDD) has been developed in China, but little is known about this platform.

Objective: The aim of this study is to investigate the characteristics, acceptance, and initial impact of IHDD during the outbreak of COVID-19 in a tertiary hospital in South China

Methods: The total number of and detailed information on online prescriptions during the first 2 months after work resumption were obtained. Patients' gender, age, residence, associated prescription department, time of prescription, payment, and drug delivery region were included in the analysis.

Results: A total of 1380 prescriptions were picked up or delivered between March 2 and April 20, 2020. The largest group of patients were $36-59$ years old $(n=680,49.3 \%)$, followed by the $18-35$ years age category $(n=573,41.5 \%)$. In total, 39.4\% $(n=544)$ of the patients chose to get their medicine by self-pickup, while $60.6 \%(n=836)$ preferred to receive their medicine via drug delivery service. The top five online prescription departments were infectious diseases $(n=572,41.4 \%)$, nephrology $(n=264$, $19.1 \%)$, endocrinology $(n=145,10.5 \%)$, angiocardiopathy $(n=107,7.8 \%)$, and neurology $(n=42,3 \%)$. Of the 836 delivered prescriptions, $440(52.6 \%)$ were sent to Guangdong Province (including 363 [43.4\%] to Shenzhen), and 396 (47.4\%) were sent to other provinces in China.

Conclusions: The IHDD platform is efficient and convenient for various types of patients during the COVID-19 crisis. Although offline visits are essential for patients with severe conditions, IHDD can help to relieve pressure on hospitals by reducing an influx of patients with mild symptoms. Further efforts need to be made to improve the quality and acceptance of IHDD, as well as to regulate and standardize the management of this novel service.

(J Med Internet Res 2020;22(8):e19678) doi: $10.2196 / 19678$

\section{KEYWORDS}

internet hospital; drug delivery; internet hospital plus drug delivery; IHDD; health management; COVID-19 


\section{Introduction}

\section{Background}

As the third largest country in the world by area, China has 34 provincial regions, over 1.4 billion people, but only 10 million licensed physicians (2.2 for every 1000 people) in 2019, according to the National Bureau of Statistics of China [1]. Since the severe acute respiratory syndrome (SARS) epidemic in 2003, the Chinese government has been rebuilding the three-tier health care system. Today, the health care system in China consists of community health centers (CHCs), and secondary and tertiary hospitals in urban areas; and village clinics, township health centers (THCs), and county hospitals in rural areas. CHCs, village clinics, and THCs are considered core primary care providers and are expected to provide affordable first contact care while secondary and tertiary care facilities provide specialist referral services [2]. However, with no gatekeeping in the primary health care system, patients can freely choose their provider at any health facility. Although many disorders could be treated by primary care providers conveniently and at a relatively low price, many patients are unwilling to see these providers owing to their lack of confidence in the health professionals' skills and the quality of health care provided. They tend to go to high-level hospitals even for mild symptoms, effectively overcrowding those hospitals [3]. On the other hand, skilled doctors are unwilling to work at the community level and in remote rural areas for financial and professional reasons. These two problems have led to countless transprovincial patients, resulting in numerous additional economic and time costs [4].

The rapid increase in internet users (from $22.7 \%$ to $59.6 \%$ of the population between 2008 and 2018) [5] offers the Chinese government a new alternative to address these health care problems. On October 25, 2014, the first officially approved "internet hospital" went online in Guangdong Province. In the beginning, the internet hospital consisted of four clinics operated by doctors from the Second People's Hospital of Guangdong Province, an online platform operated by a medical technology company, and a network of medical consulting facilities based in clinics in rural villages, $\mathrm{CHCs}$, and large pharmacy chain stores [4]. The inchoate platform usually required onsite equipment (computers, cameras, speakers, and cable network). Patients needed to go to a medical consultation facility near their home and meet through the internet with the doctor based in a top-level hospital in a big city. With the widespread adoption of smartphones and tablet computers, and the ever-increasing popularity of mobile internet communication, a mobile health (mHealth) care model was made accessible to the public. mHealth allows patients to access information, assessments, and treatments in a timely manner. In addition, it empowers doctors with another way to connect with their patients and to practice without geographical limitations [6]. Therefore, the extra costs of health care, such as those associated with travel, time, and doctor consultations, can be dramatically reduced.
During the outbreak of coronavirus disease (COVID-19) [7], the Chinese government adopted a series of administrative measures to stop the spread of the epidemic [8], including requiring domestic internet hospitals to vigorously carry out remote medical services [9]. Although the convenience and ubiquity of internet hospitals makes them a promising avenue through which to overcome geographical limitations between patients and doctors, there is still a "social distance" barrier between the patients and their prescription medicines. In order to solve this problem, many hospitals intend to cooperate with delivery companies to build a partnership for drug delivery [10]. This bundled approach could offer an omnichannel solution that can help people on their path to urgently needed health care and medicine during the epidemic.

\section{Objective}

To explore the advantages of the IHDD model for health management during public health emergencies, we analyzed the prescriptions of online outpatients at the People's Hospital of Baoan Shenzhen in Shenzhen City, Guangdong. Data from the first 2 months after work resumption were collected to reveal the characteristics, acceptance, and initial impact of the new bundled approach.

\section{Methods}

\section{Data Sources}

The total number of online prescriptions and detailed information on them were obtained automatically from the hospital information system (DTHealth, V7.0) of the People's Hospital of Baoan Shenzhen. Data from March 2 to April 20, 2020 were collected. Patients' gender, age, residence, associated prescription departments, time of prescription, payment, and drug delivery region were included in the analysis. GraphPad Prism 8.0.2 (GraphPad Software) was used to summarize and analyze the data.

\section{Ethics Statement}

Ethics approval was obtained from the medical research ethics committee of the People's Hospital of Baoan Shenzhen before the start of the study.

\section{Results}

\section{The Internet Hospital Workflow}

Figure 1 shows the online consultation workflow of the internet hospital. The patients chose a department and doctor by self-assessment using the hospital miniprogram. There was no prescription option for picture/text counseling patients. For the online clinic, a confirmation would be sent by text message once the online clinic appointment was made. Another message would be sent to the patient 3 minutes before the video counseling session began to remind them to open the hospital miniprogram in time. The doctor then initiated a video consultation with the patient and made an online prescription, if necessary, based on the diagnosis of the patient. At the payment step, the patient could choose self-pickup of medication at the hospital's pharmacy or delivery to an assigned place. 
Figure 1. Online workflow of the internet hospital.

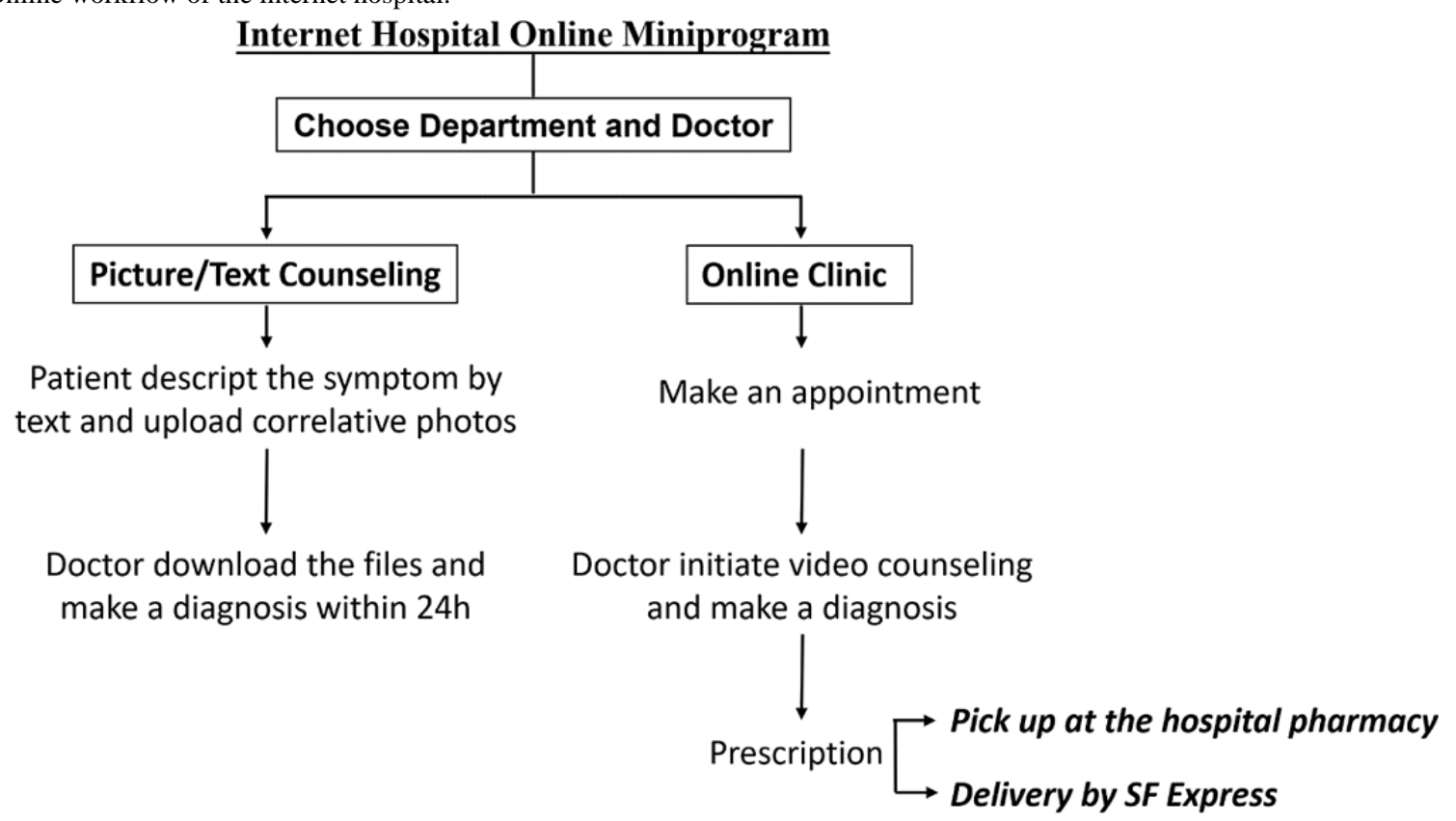

\section{Number and Payment Amount of Online Prescriptions}

A total of 1380 prescriptions were picked up or delivered between March 2 and April 20, 2020. The weekly number and payment amount pertaining to these prescriptions are summarized in Figure 2. There was an increase in the use of the online prescription service. The number and total payments of the 7th week significantly increased, by 11.3 and 4.8 times, respectively, compared with the first week.

Figure 2. The number of and total payments pertaining to online prescriptions.

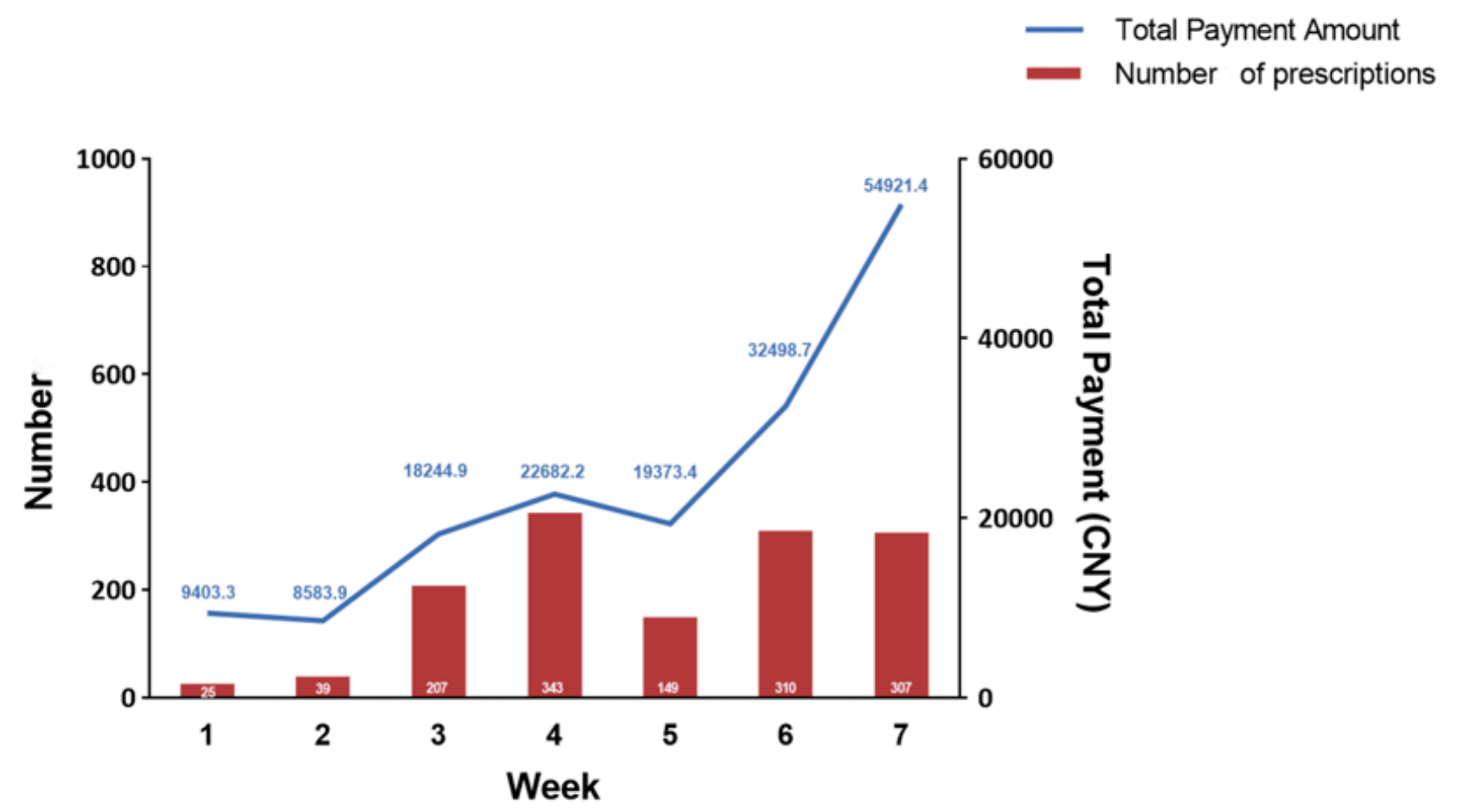

\section{Patient Characteristics}

There was no sex-based differences among the patients who received prescriptions (Table 1). The patients were divided into four groups according to their age: 1-17 years old, 18-35 years old, 36-59 years old, and $\geq 60$ years old. The largest group of patients were $36-59$ years old $(n=680,49.3 \%)$, followed by those who were $18-35$ years old ( $\mathrm{n}=573,41.5 \%)$. In total, $65.7 \%(\mathrm{n}=907)$ of the patients were local residents, $5.6 \%(\mathrm{n}=77)$ were from Guangdong cities other than Shenzhen, $28.7 \%$ $(n=396)$ were from other provinces in China. Less than half the patients $(n=544,39.4 \%)$ chose to receive their medicine by self-pickup, while $60.6 \%(n=836)$ preferred to get their medicine by drug delivery service. 
Table 1. Baseline characteristics of patients $(\mathrm{N}=1380)$.

\begin{tabular}{ll}
\hline Characteristic & Value \\
\hline Sex, $\mathbf{n}(\boldsymbol{\%})$ & $693(50.2)$ \\
Male & $687(49.8)$ \\
Female & $38(1-93)$ \\
Age (years) & \\
Median (range) & $12(0.9)$ \\
Group, $\mathbf{n}(\boldsymbol{\%})$ & $573(41.5)$ \\
$\quad 1-17$ & $680(49.3)$ \\
$\quad 18-35$ & $115(8.3)$ \\
$36-59$ & \\
$\quad$ 60 & $907(65.7)$ \\
Residence, $\mathbf{n}(\%)$ & $77(5.6)$ \\
Local (Shenzhen City) & $396(28.7)$ \\
Other cities in Guangdong Province & \\
Other provinces & $836(60.6)$ \\
Access to medicine, $\mathbf{n}(\boldsymbol{\%})$ & $544(39.4)$ \\
Delivery & \\
Self-pickup & \\
\hline
\end{tabular}

\section{Distribution of Online Prescriptions}

The top five online prescription departments were infectious diseases $(n=572,41.4 \%)$, nephrology $(n=264,19.1 \%)$, endocrinology $(\mathrm{n}=145,10.5 \%)$, angiocardiopathy $(\mathrm{n}=107,7.8 \%)$,

and neurology $(\mathrm{n}=42,3 \%)$. The majority of infectious disease and neurology patients chose drug delivery services, while most patients with other diagnoses preferred to pick up their medication (Table 2).

Table 2. Delivery/self-pickup preference of online prescription patients ( $\mathrm{N}=1380)$.

\begin{tabular}{lll}
\hline Department & Delivery $(\mathrm{n}=836), \mathrm{n}(\%)$ & Self-pickup $(\mathrm{n}=544), \mathrm{n}(\%)$ \\
\hline Infectious disease $(\mathrm{n}=572)$ & $551(96.3)$ & $21(3.7)$ \\
Nephrology $(\mathrm{n}=264)$ & $86(32.6)$ & $178(67.4)$ \\
Endocrinology $(\mathrm{n}=145)$ & $48(33.1)$ & $97(66.9)$ \\
Angiocardiopathy $(\mathrm{n}=107)$ & $37(34.6)$ & $70(65.4)$ \\
Neurology $(\mathrm{n}=42)$ & $25(59.5)$ & $17(40.5)$ \\
\hline
\end{tabular}

\section{Drug Delivery Details of Online Prescriptions}

For the 836 delivered prescriptions, $440(52.6 \%)$ were sent to Guangdong Province (including 363 [43.4\%] to Shenzhen) and $396(47.4 \%)$ were sent to other provinces in China. The top 10 provinces for out-of-province deliveries were Heilongjiang,
Hubei, Guangxi, Shandong, Jiangsu, Hunan, Shanxi, Henan, Anhui, and Jiangxi (Table 3). Most of them are located in the northeast, eastern, and central parts of China (Figure 3 and Table 3). The top 10 delivered medicines are listed in Table 4. Most of the medicines were used to treat infectious or chronic disease, which was consistent with the distribution of online prescription. 
Table 3. Out-of-province delivery details based on the geographical regions of China.

\begin{tabular}{|c|c|}
\hline Region & Patients $(\mathrm{n}=396), \mathrm{n}(\%)$ \\
\hline Northeast & $107(27.0)$ \\
\hline Eastern & $102(25.8)$ \\
\hline Central & $82(20.7)$ \\
\hline Southern & $35(8.8)$ \\
\hline Northwest & $35(8.8)$ \\
\hline Northern & $21(5.3)$ \\
\hline Southwest & $14(3.5)$ \\
\hline \multicolumn{2}{|l|}{ Top 10 provinces } \\
\hline Heilongjiang & $94(23.7)$ \\
\hline Hubei & $36(9.1)$ \\
\hline Guangxi & $33(8.3)$ \\
\hline Shandong & $27(6.8)$ \\
\hline Jiangsu & $24(6.1)$ \\
\hline Hunan & $24(6.1)$ \\
\hline Shanxi & $24(6.1)$ \\
\hline Henan & $22(5.6)$ \\
\hline Anhui & $14(3.5)$ \\
\hline Jiangxi & $14(3.5)$ \\
\hline
\end{tabular}

Figure 3. Regional distribution of prescription deliveries.

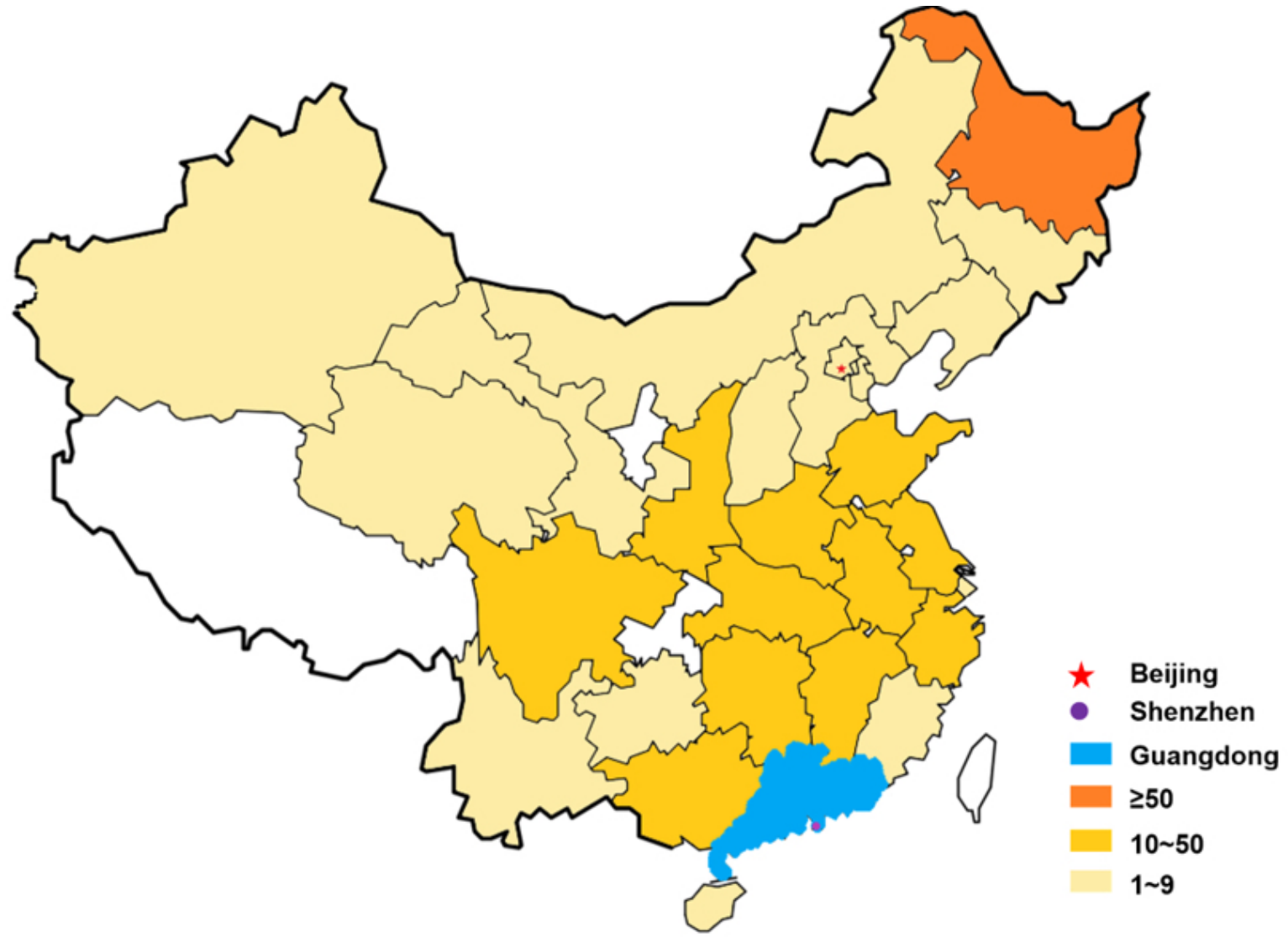


Table 4. Top 10 delivered medicines.

\begin{tabular}{lll}
\hline Name & Formulation & Manufacturer \\
\hline Entecavir & Dispersible tablet & ChiaTai TianQing \\
Metoprolol succinate & Sustained release tablet & AstraZeneca AB \\
Entecavir & Dispersible tablet & Dawnrays \\
Metformin hydrochloride & Tablet & Bristol-Myers Squibb \\
Tenofovir disoproxil fumarate & Tablet & Brilliant \\
Atorvastatin calcium & Tablet & Pfizer \\
Nifedipine & Controlled release tablet & Bayer \\
Atorvastatin calcium & Tablet & JiaLin \\
Mecobalamin & Tablet & Desano \\
Amlodipine besylate & Tablet & Pfizer \\
\hline
\end{tabular}

\section{Discussion}

\section{Principal Findings}

We conducted a pilot evaluation of the IHDD health care model in a tertiary hospital in Shenzhen during the first 2 months after work resumption. The unbalanced distribution of medical resources and the outbreak of COVID-19 [11,12] promoted the growth and exploration of more convenient internet-based medical practices [13], especially in the well-developed southern and southeastern parts of China, where people use the internet more often for medical purposes [14]. Despite the advantages of internet hospitals, access to medication remained an obstacle that may have discouraged people from using this platform. The traditional internet hospital required patients to go to the hospital or drugstore for medicines, which could cause more infections during an epidemic. The drug pickup process may increase risk of acute infectious disease, particularly for patients with suppressed immune systems or disabilities, which can then lead to severe health deterioration. On the other hand, out-of-city and out-of-province patients could have problems finding the exact prescription medications they need, as those medicines might be not available at their local hospitals and drugstores. In January 2019, the General Office of the State Council of the People's Republic of China implemented the National Centralized Drug Purchasing (NCDP) and Using pilot program and selected 11 cities (including Shenzhen) in mainland China to carry out the "4+7" City-Drug-Volume-Based-Purchasing pilot project [15]. As the "frontier" of Chinese prescription medicine reform, prescription medicines that were made by the doctors of Shenzhen's hospitals may be more affordable. Therefore, the development of IHDD could enable patients across the country to access online prescription medication in a secure and convenient way.

The Chinese government has encouraged internet hospitals to join the epidemic prevention and control efforts of the COVID-19 outbreak [16]. On March 15, 2020, the first professional standard, "Specification for Online Consultation Service for Infectious Disease Epidemic Situation" was published on the national group standard information platform of China, requiring that internet hospitals provide 24/7 online services in response to the epidemic [17]. The internet hospital of the People's Hospital of Baoan Shenzhen has been officially online since March 2, 2020. From opening to April 20, 2020, it saw a total of 8638 patients, an average of 176 per day, with 5877 in picture/text counseling and 2761 in online clinic video counseling (including 1381 that did not result in a prescription). Most of the picture/text consultations were prehospital services such as psychological counseling and medical education. The number and payment amounts of online prescriptions increased progressively from the first investigated week to the 7 th one (Figure 2), which indicates increased acceptance of IHDD. The drop in prescription numbers during the 5 th week might be the result of two factors: Tomb-Sweeping holiday and a lack of antiviral medicine.

Most prescription patients were between the ages of 18 and 60 years, had no time for onsite visitations, and had greater access to new medical platforms. At present, health authorities and the government have warned older people that they are at a higher risk of more serious and possibly fatal illness associated with COVID-19. Moreover, the global recommendation for older populations includes social isolation, which involves staying at home and avoiding contact with other people for an extended period of time [18]. Our data show that only $8.3 \%$ of IHDD users were $\geq 60$ years (Table 1 ). This may be due to differences in public acceptance. Older populations usually take more time to become familiarized with the operations of IHDD.

The stay-at-home order constrained people from going outside, which increased difficulties associated with health management, especially chronic disease management. Medical professionals at hospitals with fever clinics are required to participate in COVID-19 prevention, control, and treatment, which has reduced their concentration on other diseases. In fact, the management of chronic disease has become a crucial issue in cities with large outbreaks of COVID-19 [19]. The largest number of internet hospital prescriptions came from the department of infectious diseases, which includes acute and chronic viral hepatitis, fatty liver, alcoholic hepatitis, drug-induced liver damage, autoimmune liver disease, and genetic and metabolic liver disease. The second largest group was from nephrology, followed by endocrinology. Patients with chronic liver disease, kidney disease, or diabetes could easily renew their prescriptions and receive their medicine by IHDD. 
A notable finding was that most patients with an infectious disease chose to receive their medicine by delivery (96.3\%), whereas most patients with other diseases selected self-pickup (Table 2). This can be explained by the need for special storage of some medicines (eg, recombinant human erythropoietin for kidney disease or insulin for diabetes).

Established in 1984, the People's Hospital of Baoan Shenzhen is also the Eighth People's Hospital of Shenzhen, the Shenzhen Baoan Affiliated Hospital of Southern Medical University, and the Second Affiliated Hospital of Shenzhen University. It was recognized as a Grade A Tertiary Hospital by the Guangdong Health Department in 2012. As an important source of health care providers in Shenzhen, the hospital holds a great reputation in both basic clinical practice and diverse clinical research and training. The IHDD platform enabled patients all over the country to obtain access to its health professionals and quality-assured medicine (Figure 3). The hospital even offered medical service to the patients in Wuhan, the epicenter of COVID-19. In fact, online prescription medicines that were delivered to Hubei Province accounted for the second largest number of all out-of-province deliveries (Table 3 ). The top 10 provinces for IHDD delivery were located in the northeast, eastern, and central parts of China. One of the reasons is that these areas are relatively economically developed regions, and their residents are highly educated, which ensures they have a better understanding of the benefits of IHDD.

The top 10 delivered medicines were used for the treatment of hepatitis, hypertension, hyperlipidemia, diabetes, climacteric symptoms, etc (Table 4). This finding was consistent with the distribution of prescription departments. In fact, 7 of these departments were enrolled in the National Essential Drugs of China program. Within these 7, 3 belonged to the "4+7" NCDP catalog. The affordability and quality of these medications were guaranteed by the government.

One of the concerns of IHDD is the safety and security of drug delivery. Therefore, delivery service companies with good reputations were chosen by the hospitals as partners. As the industry leader, SF Express is the first logistics company to cooperate with both pharmaceutical providers and hospitals. It has a long history of ambient temperature and cold chain medicine transport. Moreover, it offers real-time package tracking and zero-touch delivery. Once the patients place their order, a tracking number is sent by text message to their cell phone. The processing information of the medicine is updated and sent to patients automatically. Couriers place the medicines into the customer-assigned delivery lockers, which are usually near the patient's residence, so the patient can access them using a random cipher. This process could effectively reduce viral transmission while simultaneously providing convenience for patients. At present, an advanced cooperation model is under exploration: the pharmacist-audited prescription will be sent to the manufacturer directly, and the medicines will be delivered from manufacturer's stock house. This will reduce substantial pressure on hospital drugstores and cut transportation expenses.

\section{Future Prospects}

Although in-person visits are essential when the patients are experiencing severe symptoms, IHDD can help to relieve pressure on hospitals by reducing the influx of mild cases. To make better use of IHDD during and after the current epidemic, more effort is needed. Simple and clear instructions are necessary to improve its acceptance by older people. Financial support, like adding medical insurance to payment methods, can also promote adoption by the public. The new hospital-manufacturer-patient transport model should be further evaluated. Moreover, official regulations are required in terms of standardization of the operational process and management of IHDD.

\section{Conclusion}

The pandemic of COVID-19 has clearly entered a new stage with rapid spread to countries outside China, becoming a global threat. This once-in-a-century pandemic might permanently change people's lifestyle, especially when it comes to health management. In our study, IHDD has been proven to be efficient and convenient for many types of patients during the crisis. The widespread use of this platform can help to reduce person-to-person transmission as well as the infection risk of patients with chronic diseases or disability.

\section{Acknowledgments}

This research was supported in part by the Key Laboratory of Emergency and Trauma (Hainan Medical University), the Ministry of Education (KLET-201908), and th eScience, Technology and Innovation Commission of Shenzhen Municipality (731144920168). We gratefully acknowledge the help of the Information Technology Center, People's Hospital of Baoan Shenzhen. We also thank Mr Zhiyong Zhang for assistance with data collection.

\section{Authors' Contributions}

LD, QS, and CL designed the study. QS, FC, and YL searched for relevant national and regional information. MJ and HH gathered data. ZC carried out the data analyses. LD wrote the first draft of the paper, with revisions from QS and CL. All authors contributed to revisions and approved the final version.

\section{Conflicts of Interest}

None declared.

\section{References}


1. Public Health. National Bureau of Statistics of China. 2020. URL: http://data.stats.gov.cn/english/easyquery.htm?cn=C01 [accessed 2020-04-20]

2. Yip WC, Hsiao W, Meng Q, Chen W, Sun X. Realignment of incentives for health-care providers in China. The Lancet 2010 Mar 27;375(9720):1120-1130. [doi: 10.1016/S0140-6736(10)60063-3] [Medline: 20346818]

3. Wu D, Hesketh T, Shu H, Lian W, Tang W, Tian J. Description of an online hospital platform, China. Bull World Health Organ 2019 Aug 01;97(8):578-579 [FREE Full text] [doi: 10.2471/BLT.18.226936] [Medline: 31384077 ]

4. Tu J, Wang C, Wu S. The internet hospital: an emerging innovation in China. The Lancet Global Health 2015 Aug;3(8):e445-e446 [FREE Full text] [doi: 10.1016/S2214-109X(15)00042-X] [Medline: 26187488]

5. Work dynamics. Ministry of Industry and Information Technology of the People's Republic of China. URL: http://www. miit.gov.cn/n1146290/n1146402/index.html [accessed 2020-04-20]

6. Whitehead L, Seaton P. The Effectiveness of Self-Management Mobile Phone and Tablet Apps in Long-term Condition Management: A Systematic Review. J Med Internet Res 2016 May 16;18(5):e97 [FREE Full text] [doi: 10.2196/jmir.4883] [Medline: 27185295]

7. Sohrabi C, Alsafi Z, O'Neill N, Khan M, Kerwan A, Al-Jabir A, et al. World Health Organization declares global emergency: A review of the 2019 novel coronavirus (COVID-19). Int J Surg 2020 Apr 26;76:71-76 [FREE Full text] [doi: 10.1016/j.ijsu.2020.02.034] [Medline: 32112977]

8. Wu Z, McGoogan JM. Characteristics of and Important Lessons From the Coronavirus Disease 2019 (COVID-19) Outbreak in China: Summary of a Report of 72314 Cases From the Chinese Center for Disease Control and Prevention. JAMA 2020 Feb 24;323(13):1239-1242. [doi: 10.1001/jama.2020.2648] [Medline: 32091533]

9. Gong K, Xu Z, Cai Z, Chen Y, Wang Z. Internet Hospitals Help Prevent and Control the Epidemic of COVID-19 in China: Multicenter User Profiling Study. J Med Internet Res 2020 Apr 14;22(4):e18908 [FREE Full text] [doi: 10.2196/18908] [Medline: 32250962]

10. Hong Z, Li N, Li D, Li J, Li B, Xiong W, et al. Telemedicine During the COVID-19 Pandemic: Experiences From Western China. J Med Internet Res 2020 May 08;22(5):e19577 [FREE Full text] [doi: 10.2196/19577] [Medline: 32349962]

11. Mahase E. WHO declares pandemic because of "alarming levels" of spread, severity, and inaction. BMJ 2020 Mar 12;368:m1036. [doi: 10.1136/bmj.m1036] [Medline: $\underline{\text { 32165426] }}$

12. Bedford J, Enria D, Giesecke J, Heymann DL, Ihekweazu C, Kobinger G, et al. COVID-19: towards controlling of a pandemic. The Lancet 2020 Mar 17;395(10229):1015-1018. [doi: 10.1016/S0140-6736(20)30673-5] [Medline: 32197103]

13. Tanne JH, Hayasaki E, Zastrow M, Pulla P, Smith P, Rada AG. Covid-19: how doctors and healthcare systems are tackling coronavirus worldwide. BMJ 2020 Mar 18;368:m1090. [doi: 10.1136/bmj.m1090] [Medline: $\underline{32188598}$ ]

14. Xie X, Zhou W, Lin L, Fan S, Lin F, Wang L, et al. Internet Hospitals in China: Cross-Sectional Survey. J Med Internet Res 2017 Jul 04;19(7):e239 [FREE Full text] [doi: 10.2196/jmir.7854] [Medline: 28676472]

15. Tang M, He J, Chen M, Cong L, Xu Y, Yang Y, et al. "4+7" city drug volume-based purchasing and using pilot program in China and its impact. Drug Discov Ther 2019;13(6):365-369 [FREE Full text] [doi: 10.5582/ddt.2019.01093] [Medline: $\underline{31956236]}$

16. Notice on accomplishing online consultation services in the epidemic prevention and control (Medical Letter 2020 No. 112). National Health Commission of the People's Republic of China. 2020 Feb 7. URL: http://www.nhc.gov.cn/yzygj/ s7652m/202002/32c3e98988894fa18280e4543d2710c7.shtml [accessed 2020-04-20]

17. Specification for online consultation service for infectious disease epidemic situation. Zhejiang Digital Economy Association. 2020 Mar 15. URL: http://www.ttbz.org.cn/StandardManage/Detail/33876/ [accessed 2020-04-20]

18. Brooke J, Jackson D. Older people and COVID-19: Isolation, risk and ageism. J Clin Nurs 2020 Jul;29(13-14):2044-2046. [doi: 10.1111/jocn.15274] [Medline: 32239784]

19. Shahid Z, Kalayanamitra R, McClafferty B, Kepko D, Ramgobin D, Patel R, et al. COVID-19 and Older Adults: What We Know. J Am Geriatr Soc 2020 May;68(5):926-929 [FREE Full text] [doi: 10.1111/jgs.16472] [Medline: 32255507]

\author{
Abbreviations \\ CHC: community health center \\ COVID-19: coronavirus disease \\ IHDD: internet hospital plus drug delivery \\ mHealth: mobile health \\ NCDP: National Centralized Drug Purchasing \\ SARS: severe acute respiratory syndrome \\ THC: township health center
}


Edited by G Eysenbach; submitted 29.04.20; peer-reviewed by H Liu, F Zhang, X Xie, B Foroutan; comments to author 12.06.20; revised version received 22.06.20; accepted 23.07.20; published 06.08.20

Please cite as:

Ding L, She Q, Chen F, Chen Z, Jiang M, Huang H, Li Y, Liao C

The Internet Hospital Plus Drug Delivery Platform for Health Management During the COVID-19 Pandemic: Observational Study $J$ Med Internet Res 2020;22(8):e19678

URL: http://www.jmir.org/2020/8/e19678/

doi: $10.2196 / 19678$

PMID: 32716892

(CLiang Ding, Qiuru She, Fengxian Chen, Zitong Chen, Meifang Jiang, Huasi Huang, Yujin Li, Chaofeng Liao. Originally published in the Journal of Medical Internet Research (http://www.jmir.org), 06.08.2020. This is an open-access article distributed under the terms of the Creative Commons Attribution License (https://creativecommons.org/licenses/by/4.0/), which permits unrestricted use, distribution, and reproduction in any medium, provided the original work, first published in the Journal of Medical Internet Research, is properly cited. The complete bibliographic information, a link to the original publication on http://www.jmir.org/, as well as this copyright and license information must be included. 